Cahiers $d u$ MONDE RUSSE

\section{Cahiers du monde russe}

Russie - Empire russe - Union soviétique et États indépendants

$52 / 4 \mid 2011$

Varia

\title{
Maria Botchkareva, Yashka. Journal d'une femme combattante
}

\section{Thomas Chopard}

\section{OpenEdition \\ Journals}

Édition électronique

URL : http://journals.openedition.org/monderusse/7606

DOI : $10.4000 /$ monderusse. 7606

ISSN : $1777-5388$

\section{Éditeur}

Éditions de l'EHESS

\section{Édition imprimée}

Date de publication : 20 décembre 2011

Pagination : 722-724

ISBN : 978-2-7132-2353-2

ISSN : $1252-6576$

\section{Référence électronique}

Thomas Chopard, «Maria Botchkareva, Yashka. Journal d'une femme combattante », Cahiers du monde russe [En ligne], 52/4 | 2011, mis en ligne le 29 novembre 2012, Consulté le 25 septembre 2020 URL : http://journals.openedition.org/monderusse/7606; DOI : https://doi.org/10.4000/monderusse. 7606

Ce document a été généré automatiquement le 25 septembre 2020.

(c) École des hautes études en sciences sociales 


\title{
Maria Botchkareva, Yashka. Journal d'une femme combattante
}

\author{
Thomas Chopard
}

\section{RÉFÉRENCE}

Maria BotCHKAREVA, Yashka. Journal d'une femme combattante, Russie 1914-1917

(Édition présentée par Stéphane Audoin-Rouzeau et Nicolas Werth). Paris : Armand

Collin, 2012, $301 \mathrm{p}$.

1 Cette nouvelle parution consiste en la réédition des souvenirs de Marija Bočkareva, parus en anglais en 1919 et en français en 1923, dans la même traduction. Contrairement au titre (probablement soumis à la fantaisie de l'éditeur), l'ouvrage consiste, non pas en un journal mais en des souvenirs, écrits a posteriori, comme en témoigne le titre de l'édition de 1923 : Yashka: Ma vie de soldat. Souvenirs de la Guerre, de la Révolution, de la Terreur en Russie.

2 Si le récit s'apparente par bien des aspects à la nébuleuse infinie des témoignages et souvenirs russes consécutifs à la révolution, son contenu est singulier. Marija Bočkareva fait en effet partie de cette minorité de femmes à avoir combattu sous l'uniforme russe pendant la Première Guerre mondiale. Elle a ensuite été à l'origine, en 1917, d'une expérience inédite : la création de bataillons exclusivement féminins. Même si cette innovation tient une place majeure dans le témoignage, celui-ci offre un triptyque : la Grande Guerre, l'année 1917 et les bataillons féminins, et enfin leur démantèlement dans la tourmente d'Octobre avant le départ pour les États-Unis.

3 L'introduction de Nicolas Werth et de Stéphane Audoin-Rouzeau permet une lecture éclairée des différents souvenirs rapportés par l'ouvrage; les références bibliographiques (en particulier les travaux de Laurie Stoff, symétrique historiographique de cette source), en note, font état de la recherche sur le sujet. La biographie complète de cette femme soldat est fine et détaillée : ses origines paysannes, sa rupture avec sa famille qui la fait côtoyer, déjà avant la guerre, des milieux 
masculins en marge de la société, et surtout, après son retour en Russie en 1918, la fin de sa vie, abrégée par une balle de la Čéka. Elle souligne aussi les conditions singulières de leur écriture par un journaliste américain, sous la dictée de M. Bočkareva, ainsi que l'écho relativement important que l'expérience des bataillons féminins a suscité, en particulier dans les mouvements féministes occidentaux. Tout est fait pour que les multiples niveaux de lecture de la source soient déployés. Le parcours de Marija Bočkareva est ainsi tout à la fois celui d'un soldat de la Première Guerre mondiale, d'une femme en arme et d'un acteur de la révolution de 1917.

La description du front russe de 14-18, souvent méconnu, se déploie longuement dans le témoignage. L'impréparation générale, l'improvisation sont largement évoquées. Mais ce sont surtout les conditions de vie du soldat russe qui frappent : la promiscuité, la précarité et la saleté des infrastructures, y compris au front, avec des tranchées tout juste creusées, loin des images du front français, choquent même l'auteur d'origine paysanne. Le lecteur trouvera toutefois peu de matières à une étude du combat sur le front russe. Si Bočkareva porte l'uniforme, son expérience du feu reste limitée; elle s'apparente bien plus à une mascotte au sein de son régiment qu'à une combattante à temps plein. Elle témoigne toutefois de la violence des rares affrontements, parfois au corps à corps, auxquels elle participe. Son rôle ponctuel d'infirmière permet aussi d'appréhender l'impact du feu sur ses compagnons d'arme. La constitution progressive des bataillons féminins en mars 1917 n'offre pas une expérience combattante plus importante : l'envoi d'un nombre relativement restreint de volontaires au front (pas plus de 300), se solde par un massacre des soldates.

5 Le témoignage étant écrit après 1917, c'est surtout l'effondrement progressif de l'Empire russe qu'il reflète : son incapacité à mobiliser hommes et matériel dans une guerre moderne, la dégradation du moral des troupes sous l'effet des rumeurs (en particulier relatives à la famille impériale) et des défaites, etc. La rupture de 1917 est rendue particulièrement visible: l'irruption des comités de soldats et l'abolition des anciennes règles de disciplines militaires, introduite par le prikaz $\mathrm{n}^{\circ} 1$, affectent profondément la vie des armées; l'humeur des soldats, leur ressentiment croissant à l'égard des officiers et des "bourgeois ». Le regard de Bočkareva est d'autant plus attentif à ces changements qu'elle témoigne d'une hostilité profonde aux acquis de la révolution, y voyant un ferment du désordre et une manière de se dérober au combat.

Mais l'un des aspects les plus intéressants de ce témoignage consiste en la brèche symbolique importante dans la domination masculine que constitue le fait, pour une femme, de porter les armes, d'abord individuellement, puis au sein de bataillons exclusivement féminins. L'introduction s'attarde consciencieusement sur le phénomène omniprésent, quoique très minoritaire, des femmes soldates au cours du conflit mondial; cette rareté en Europe marque une rupture dans l'invariante possession masculine des armes. Mais le témoignage de Marija Bočkareva souligne surtout l'impossibilité pour une femme d'endosser le modèle viril du guerrier: l'importance de son surnom masculin - Yaška - aux armées, son exclusion variable du combat; et, surtout, l'opprobre que suscite la création de ses bataillons féminins, avec l'assentiment du ministre de la Guerre. L'incompatibilité entre la féminité et la guerre ne s'illustre pas seulement dans les mille et une entraves que rencontre Yaška et ses bataillons; le témoignage à la première personne permet aussi de le saisir dans les représentations et les aveux d'une soldate. 
$7 \quad$ Il est toutefois un aspect de l'expérience de Yaška que l'introduction ne relève pas et qu'une histoire de la virilité et de la valence différentielle des sexes n'épuise pas, c'est celui de l'expérience de guerre des femmes présentes au front, combattantes ou non. Celles-ci ont eu à charrier, au cours des trois années de guerre, une réputation de dépravation sexuelle qui reflétait en large partie la licence sexuelle qui régnait au front, y compris à l'encontre des civiles de l'Empire russe. Les femmes au front, en particulier les infirmières, étaient rapidement assimilées à l'arrière à des « femmes du régiment" et, à l'inverse, les prostituées de Petrograd adoptaient les atours des infirmières pour se mettre au diapason de la guerre. Les insultes à caractère sexuel que subissent Yaška et ses compagnonnes ne consistent pas seulement en une violence symbolique excluant les femmes de la sphère guerrière, elles sont aussi la continuation de violences physiques et d'une sexualité en campagne qui détonent singulièrement avec la situation sur le front français et qui se poursuivra tout au long de la guerre civile.

8 Au final, l'ouvrage reste une source intéressante pour ceux qui souhaitent aborder aussi bien la question des violences de guerre en général, et de la Première Guerre mondiale en particulier, que la configuration singulière dans la domination masculine que représentent les violences exercées par les femmes. Le témoignage de Yaška présente la particularité de combiner l'expérience de mobilisation du plus grand nombre et la singularité d'une expérience inédite. Reste à mentionner que son découpage en chapitres courts et son style plat et franc rendent la lecture aisée. 